\title{
The Use of Adipose Tissue-Derived Progenitors in Bone Tissue Engineering - a Review
}

\author{
Indranil Bhattacharya Chafik Ghayor Franz E. Weber \\ Oral Biotechnology \& Bioengineering, Cranio-Maxillofacial and Oral Surgery, Center for Dental Medicine, University of Zurich, \\ Zurich, Switzerland
}

\section{Keywords}

Bone regeneration - Adipose tissue-derived stem cells . Epigenetics

\section{Summary}

2500 years ago, Hippocrates realized that bone can heal without scaring. The natural healing potential of bone is, however, restricted to small defects. Extended bone defects caused by trauma or during tumor resections still pose a huge problem in orthopedics and cranio-maxillofacial surgery. Bone tissue engineering strategies using stem cells, growth factors, and scaffolds could overcome the problems with the treatment of extended bone defects. In this review, we give a short overview on bone tissue engineering with emphasis on the use of adipose tissue-derived stem cells and small molecules.

(C) 2016 S. Karger GmbH, Freiburg

\section{Introduction}

Bone tissue has a unique ability to remodel and heal naturally without leaving any scar; however, $10 \%$ of large bone defects cannot heal naturally, and this requires an urgent need of either surgery or bone transplantation [1]. It has been reported that segmental bone defects which are most commonly found in the tibia may result in amputation if structural integrity of the bone cannot be restored and maintained [2].

Bone is the most commonly transplanted tissue, and about 1 million patients undergo surgical bone reconstruction annually in Europe. In the European Union, 22 million women and 5.5 million men are estimated to have osteoporosis; and 3.5 million new fragility fractures were sustained [3]. With the rise in life expectancy, the incidences of bone-related injuries in an ageing population are on the rise and are reaching epidemic proportions [4]. Thus efficient ways to treat bone injuries need to be urgently addressed.

Regenerative medicine deals with repairing or replacing the damaged tissues or organs, with scaffolds, cells, and growth factors in any combination or individually to fully restore the injured tissue's structure and function. This combination of cells, growth factors, and scaffolds is often referred to as the tissue engineering triad [5] (fig. 1).

Within this field lies the branch of bone regeneration also known as bone tissue engineering. Bone tissue engineering is quite advanced compared to other tissue engineering fields, due to the fact that bone itself has a high regenerative potential since it undergoes a continuous remodeling and turn-over process. The classical work by Urist [6] back in 1965 demonstrated that bone has autoinduction ability, and new bone formation can be induced from injured bone tissue. Over the years, we now know much more about the inducers of bone formation which include growth factors and about the cells which are induced to differentiate to bone cells. Osteoblasts, the bone-forming cells are derived from the mesenchymal lineage; therefore mesenchymal stromal cells (MSCs; also known as mesenchymal stem cells) harvested from sources like bone marrow or fat tissue are widely used in bone regeneration. These cells dock on the scaffolds, which are osteoconductive, and then the growth factors induce these osteogenic cells leading to the ingrowth of bone into $3 \mathrm{D}$-structures, preferentially leading to creeping substitution.

Bone autograft is the gold standard scaffold and is still considered the safest and the most effective treatment of large bone defects. This uses patient's own autologous bone, which provides a natural substrate for new osteogenic cells to grow into the graft enabling the healing and re-modeling of the injured bone [7]. However, a major drawback with autografts involves pain and infection around the donor bone area, the limitation in donor bone volume (only $20 \mathrm{~cm}^{3}$ ) and incomplete integration of the grafted bone [8]. Thus bone tissue engineering seems to be a promising therapeutic alternative as it would drastically eradicate the pain and overcome the limitation caused by autografts.

\section{KARGER}

() 2016 S. Karger GmbH, Freiburg

Fax +497614520714 
Fig. 1. Core components of tissue engineering. The scaffold, cells, and growth factors are required for the development of tissue regeneration, and these components are dependent on each other for effective tissue healing.

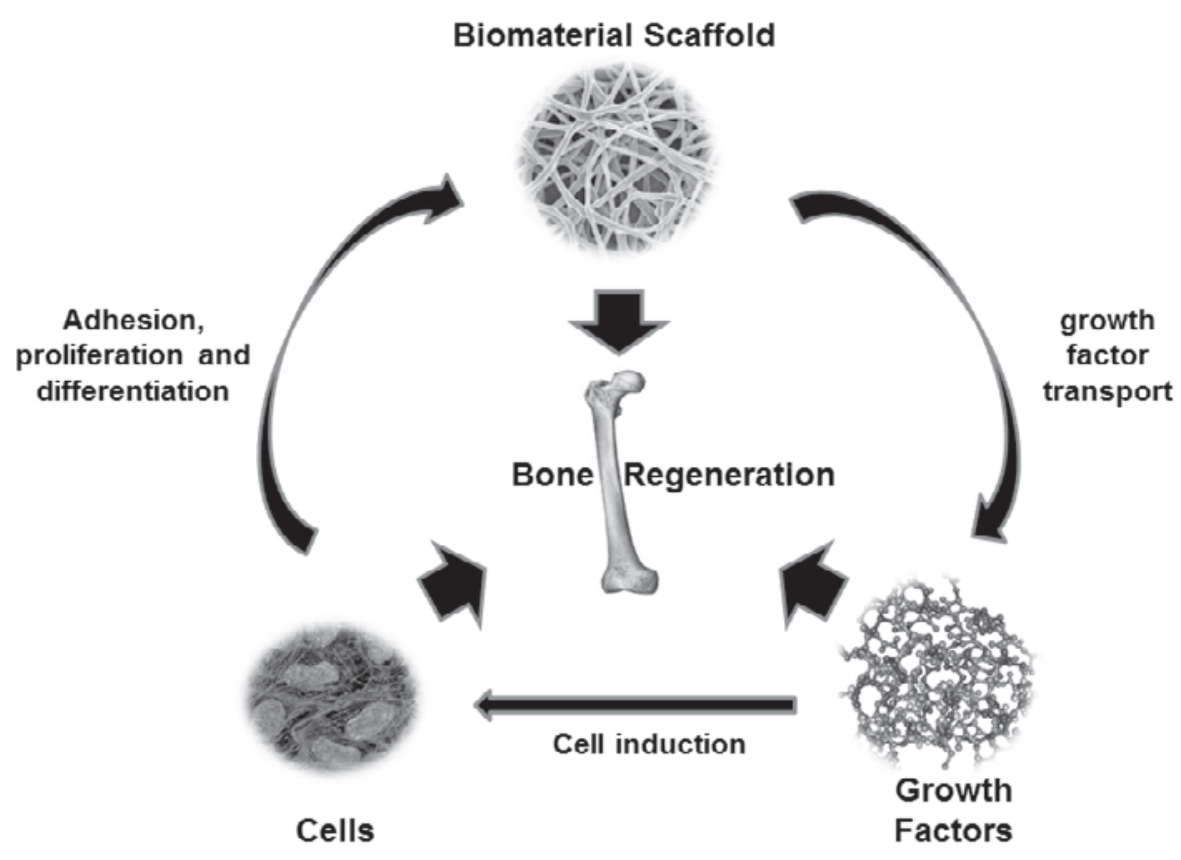

Presently, numerous materials are being investigated for their ability to function as scaffolds which have the characteristic to mimic the composition of bone (i.e. calcium phosphate and collagen). Most materials can be chemically treated or biologically functionalized with peptides to enhance their osteoconductivity, degradability, and angiogenic response. More importantly, the scaffold should provide a proper environment for homing, proliferation, differentiation, and migration of osteogenic and other cells associated with bone regeneration.

MSCs derived from bone marrow (mostly from iliac-crest aspirates) are commonly used in bone tissue engineering. MSC-based cell therapy has the potential to promote bone regeneration and has been well studied [9]. However, the stem cells originating from other sources, such as periosteum-derived or adipose tissue-derived stem cells (ADSCs), can also support bone regeneration [7]. These cells express the classical MSC markers, have the ability to differentiate into osteogenic cells, and contribute extensively to bone regeneration in vivo. Bone tissue engineering thus involves isolation of the MSCs and their in vitro culturing on biomaterials to obtain a proper colonization and differentiation of the cells so that the biomaterial-cell construct could then be implanted in the injured area of the bone.

Various growth factors are being investigated to make the biomaterials osteoinductive. Bone morphogenetic proteins (BMPs), members of the TGF- $\beta$ superfamily, are natural and the most common growth factors responsible for osteoinduction, which is the differentiation of MSCs to bone forming cells and are able to induce bone formation even at ectopic sites. Notably BMP-2 has shown to be highly osteoinductive and is currently approved for spinal fusion and open tibia fractures, although application of high-doses of BMP alone has proven not to be safe as initially believed [10]. Bone vascularization is integral to the bone regeneration process where angiogenic growth factors, such as vascular endothelial growth factor (VEGF), are involved. For effective bone vascularization and regeneration, the crosstalk between endothelial and osteogenic progenitor cells is essential which involves a multitude of signaling growth factors such as VEGF, fibroblast growth factor (FGF), the transforming growth factor (TGF) superfamily (BMP-2, BMP-7, BMP-9, TGF- $\beta$ ) and receptor activator of nuclear factor kappa ligand (RANKL) [11]. These growth factors released by different cells trigger bone formation leading to effective bone regeneration.

In this review, we would look at the scaffolds and the cells. In particular, this review seeks to discuss the ability of ADSCs, which could differentiate into osteogenic cells. We also discuss the role of small molecules and their contribution in enabling bone regeneration.

\section{Scaffolds}

Scaffolds essentially resemble a bioreactor. They act as an osteoconductive template for bone tissue formation where osteogenic progenitor cells (generally MSCs) are seeded in vitro with or without growth factors and then implanted into an injured area or they could be implanted directly into the injured site for bone regeneration. Moreover, scaffolds provide the appropriate homing space for transplanted cells and help retain the endogenous cells together with appropriate mechanical cues and biological triggers.

To be suitable as a scaffold, a material needs to fulfill the following requirements [2]:

- Biocompatibility: Cells should adhere to scaffolds, function and metabolize normally, proliferate, and migrate. Scaffolds should give rise to minimal immunologic reaction.

- Biodegradability: Scaffold should eventually be replaced by body's own cells. Moreover, the by-products of the degraded scaffold should be non-toxic, and the body should be able to clear it up without much interference with other organs. 
Table 1. Advantages and disadvantages of various biomaterials

\begin{tabular}{|c|c|c|}
\hline Biomaterial & Advantages & Disadvantages \\
\hline Ceramics & $\begin{array}{l}\text { Widely used for bone regeneration and display good bone integration } \\
\text { High mechanical stiffness } \\
\text { Excellent biocompatible } \\
\text { Enhance osteoblast differentiation and proliferation }\end{array}$ & $\begin{array}{l}\text { Very low elasticity } \\
\text { Hard brittle surface } \\
\text { Lack remodeling ability } \\
\text { Slow rate of degradation }\end{array}$ \\
\hline Synthetic polymers & $\begin{array}{l}\text { Fabricated with tailored architecture } \\
\text { Controlled degradation }\end{array}$ & $\begin{array}{l}\text { Risk of rejection due to reduced bioactivity } \\
\text { The degradation by-products could cause cellular damage } \\
\text { and tissue necrosis }\end{array}$ \\
\hline Natural polymers & $\begin{array}{l}\text { Biologically active } \\
\text { Promote excellent cellular adhesion } \\
\text { Biodegradable } \\
\text { Minimal adverse immunological response }\end{array}$ & $\begin{array}{l}\text { Difficulty in fabricating scaffold homogenously and } \\
\text { reproducibly } \\
\text { Poor mechanical properties }\end{array}$ \\
\hline
\end{tabular}

- Mechanical integrity: Scaffold should possess the desired mechanical strength to withstand the stress from the time of implantation to the completion of bone regeneration. Moreover, the scaffold should match its mechanical property to the injured bone where it would be implanted.

- Architecture: Scaffolds should be able to support cell infiltration and vascularization. They should have optimal pore size, an interconnected pore structure, and high porosity for cells, nutrients and waste products passage. They should have the strength to bear pressure and mechanical stress.

- Manufacturing technology: Scaffold should be easily manufactured and be cost-effective. They should be scalable, and adjustments in scaffold technology should be easy to perform.

Scaffolds can be fabricated with biomaterials. The concept of a biomaterial has been defined as 'a substance that has been engineered to take a form which is used to direct, by control of interactions with components of living systems, the course of any therapeutic or diagnostic procedure' [12]. Presently, mainly 4 individual groups of biomaterials are being used in the fabrication of scaffolds. These are i) ceramics such as calcium phosphate, hydroxyapatite (HA), and tri-calcium phosphate (TCP); ii) synthetic polymers such as polystyrene, poly-l-lactic acid (PLLA), polycaprolactone (PCL), and polyglycolic acid; iii) natural polymers such as collagen, glycosaminoglycan, chitosan, hyaluronic acid, fibrin, and elastin; and iv) metals like titanium and magnesium.

A list of these biomaterials along with their advantages and disadvantages is presented in table $1[2,5]$. Since these biomaterials have their characteristic advantages and disadvantages, hence the development of composite scaffolds is gaining more interest. Composite scaffolds are in general a combination of biomaterials. For example, a combination of ceramic and polymer scaffold [13] or a combination of ceramic, synthetic polymer and natural polymer biomaterials [14]. Since natural biomaterials lack the required mechanical strength, a collagen and nano-hydroxyapatite-based scaffold with adequate mechanical strength having high porosity and interconnected pore structure is a valid model [15]. Such a composite scaffold facilitates improved cellular infiltration and vascularization. Although composite scaffolds have shown some promise, they might contain components which are not found naturally and hence they have associated problems with biocompatibility and immunologic response.

Recent research in bone tissue engineering has also investigated the development of three dimensional (3D) scaffolds resembling more the natural situation. In this regard, additive manufacturing $(\mathrm{AM})$, the computer-directed process of 3D layer-by-layer model fabrication has seen some interesting development [2]. This 3D scaffold development technology offers the potential for fabrication of implants of exquisite complexity and preciseness that could range from permanent to biodegradable and that could be implanted at the injured bone site. Additive manufacturing enables personalized treatment, which could be a great benefit for the treatment of special types of bone defects.

\section{Bone Marrow Cells}

MSCs, originally also called bone marrow (BM) stromal cells, were for the first time isolated from bone marrow by Friedenstein et al. [16], in 1976 and has since then been considered the progenitor cells for skeletal tissues. MSCs are defined as plastic culture adhesive cells with an inherent characteristic to be colonogenic and multipotent and can differentiate into several mesodermal cell lineages including osteoblasts, chondrocytes, adipocytes, tenocytes, and myoblasts. MSCs are typically identified by their expression of CD90, CD105, CD73 and CD146, and the absence of CD45, CD34, CD14, CD11b, CD79a, CD19 and HLA-DR [17]. A common source for aspirating the MSCs is the iliac crest. These aspirated cells are then grown and expanded in vitro and then seeded on selected scaffolds and cultured with the aim of having a homogeneous distribution of cells that are metabolically active. The evalua- 
tion of the osteogenic potential of the cells inside the scaffold can be made indirectly, by measuring osteo-specific secreted proteins, such as osteocalcin, or by performing the bone-specific gene expressional analysis [7].

There are many parameters that contribute towards the housing of the MSCs in the scaffolds. Firstly, the MSCs should adhere properly to the scaffold. Secondly, the cell/biomaterial volume ratio is highly critical. Thirdly, high porosity and permeability of scaffolds could help the MSCs to have a uniform cell invasion, in vivo tissue ingrowth, vascularization, and osteogenesis. Fourthly, there should be a high degree of freedom for tissue ingrowth through intergranular spaces between particulate scaffolds [7].

Some studies have reported that the effectiveness of cell-based therapy at the site of the injury is inhibitory/detrimental to tissue development. However, delayed injection of MSCs after the settling of initial acute-phase inflammation has shown enhanced repair of damaged tissue compared to 'time-of-trauma' application. Moreover, enhanced reparation is observed when cells are introduced subcutaneously, intravenously as well as directly to the wound site [18]. Due to regulatory issues, fracture fixation, stem cell harvesting, and application should be performed during a single operation.

Bioceramic scaffold when treated with fresh autologous bone marrow aspirate that is a rich source of MSCs and growth factors has been shown to be as effective as autologous bone grafting in spinal fusion procedures [19]. Even though osteogenic cells are important for bone regeneration, some studies have shown that ceramic bone substitutes alone or calcium phosphate cement application can heal adequately without the need of bone marrow aspirate to treat benign bone cavity or tibial plateau fractures [20, 21]. Thus the kind of biomaterial and the progenitor cells to be used may probably be dependent on the type and location of the bone defect.

\section{Adipose Tissue-Derived Stem Cells}

Due to its abundance, ease to harvest, minimal morbidity and high colonogenic ability, adipose tissue is a convenient source for isolation and culturing of ADSCs that could be used in regenerative medicine and tissue engineering [22, 23]. ADSCs are a type of MSCs, and they possess robust osteogenic potency. ADSCs can be maintained longer in culture and possess a higher proliferation capacity compared to bone marrow-derived MSCs [24]. The stromal vascular fraction (SVF) of the adipose tissue is generally used for isolation of the progenitor cells that could be differentiated to both osteogenic and endothelial cells [22] both of which are important for bone regeneration.

The white adipose tissue, which is the main adipose tissue in the human body, is an interesting reservoir for stem cells. Within the white adipose tissue, more ADSCs reside in the subcutaneous depots compared with the depots of visceral fat. ADSCs have also been reported in brown fat depots but not much is known about it [24]. The secretome of the ADSCs contains different endocrine factors (adipokines) with bone remodeling activity. In particular, VEGF present in the secretome contributes greatly in the repair of fractures or bone defects. Moreover, VEGF triggers angiogenesis, which is important for bone regeneration. However, much more research needs to be performed on the in vivo bone-forming potential of ADSCs and their utilization in bone tissue engineering [22].

Although the MSCs from bone marrow and adipose tissue are considered quite similar, there is a growing appreciation of possible innate differences in their biology and response to growth factors. Moreover, microarray analysis indicated that bone marrowderived MSCs and ADSCs demonstrate differentially expressed genes [25]. Studies have shown that their osteogenic response to platelet-derived growth factor BB (PDGF-BB) is markedly different. The bone marrow-derived MSCs had no effect to PDGF-BB while ADSCs exhibited enhanced mineralization, produced more calcium per cell, and upregulated osteogenic genes in response to physiological concentrations of PDGF-BB; and this effect was mediated via its receptor PDGFR- $\beta$ [26].

Materials using fabricated poly(propylene fumarate)-based $3 \mathrm{D}$ scaffolds with an ability to slowly release BMP-2 in the presence of human ADSCs have shown to be highly osteogenic and have the potential to be used as an effective reconstruction tool for cranial defects [27]. These authors used biodegradable poly lactic-co-glycolic acid (PLGA) microspheres containing BMP-2 to create a drug-releasing scaffold and this was shown to be effective for treating extended bony defects [27].

Controlled delivery of BMP-2 from gelatin hydrogel had a significant effect on human ADSC osteogenic differentiation compared to exogenous BMP-2. Moreover, lower dose of BMP-2 had a striking effect [28]. Co-expression of BMP-2 and Runx2 in ADSCs caused significantly increased bone regeneration [29]. Similarly, ADSCs expressing both LIM-1 and HIF-1a had elevated levels of BMP-2 and Runx2 and increased osteogenesis in vivo compared with either LIM-1 or HIF-1 $\alpha$ alone [30].

Studies have been performed which showed the advantage of using ADSCs in combination with biomimetic scaffold. An in vitro study using porcine ADSCs have shown their high osteogenic differentiation rate on polycaprolactone- $\beta$-tricalcium phosphate-collagen scaffolds. This was indicated by high alkaline phosphatase (ALP) activity, osteocalcin expression, and mineralization [31]. Using akermanite-based scaffolds, Zanetti and colleagues [32] have shown that ADSCs cultured for 21 days in osteogenic medium before seeding them on the scaffold have greater calcium deposition and osteocalcin expression and low IL-6 expression, compared with cells seeded on polycaprolactone- $\beta$-tricalcium phosphate. In an interesting study by Fröhlich and colleagues [33], ADSCs seeded on decellularized native bone scaffolds which provided the necessary structural and mechanical environment for osteogenic differentiation showed increased construct cellularity and elevated amounts of bone matrix components (collagen, bone sialoprotein, and osteopontin). This was achieved in 5 weeks after the addition of osteogenic supplements (dexamethasone, sodium$\beta$-glycerophosphate, and ascorbic acid-2-phosphate) to culture 
Table 2. The use of ADSCs together with various scaffolds in in vivo animal models

\begin{tabular}{lll}
\hline Animal model & Scaffold & Result \\
\hline hADSCs subcutaneously in BalB/c nude mice & $\begin{array}{l}\text { polylacticcoglycolic acid (PLGA) with } \\
\text { bone forming peptide and poly- } \\
\text { dopamine film }\end{array}$ & superior ectopic bone formation \\
\hline $\begin{array}{l}\text { hADSCs mixed with porcine atelocollagen in } \\
\text { BalB/c nude mice calvarium }\end{array}$ & nanohydroxyapatite & [55] \\
$\begin{array}{l}\text { Mouse ADSCs in femoral segmental critical-sized } \\
\text { defect in mouse }\end{array}$ & sterile cancellous bone & $\begin{array}{l}\text { osteogenesis of transplanted ADSCs and } \\
\text { thick new bone formation }\end{array}$ \\
\hline $\begin{array}{l}\text { Rat miR-135 transduced ADSCs in critical-sized } \\
\text { calvarial defect in rats }\end{array}$ & poly(sebacoyl diglyceride) bone formation not only at the bony & edges but also inside the scaffold \\
\hline $\begin{array}{l}\text { Rat ADSCs in rotator cuff model in rat } \\
\text { [58] }\end{array}$ & $\begin{array}{l}\text { multilayered PLGA nanofibers with } \\
\text { fibrin matrix with BMP2 }\end{array}$ & $\begin{array}{l}\text { new bone formation } \\
\text { BMP2 }\end{array}$ \\
\hline
\end{tabular}

medium. In table 2, we list some of the studies performed with ADSCs in animal models and the type of scaffold used. Most of these studies suggest that ADSCs from human or murine sources in combination with different scaffolds could lead to effective osteogenesis and bone regeneration.

Recently, Silva and colleagues [34] demonstrated that human ADSCs differentiate towards the osteogenic phenotype when cultured in a bioactive glass scaffold as indicated by significant increase in cell proliferation and viability, along with increased ALP activity and the expression of osteospecific proteins such as osteocalcin and osteopontin. One of the major limitations of such cellular growth on scaffolds is the lack of angiogenesis. However, implantation of porous $3 \mathrm{D}$ constructs cultured with cells from stromal vascular fraction (SVF) of adipose tissue into nude mice were able to generate bone tissue and fully functional blood vessels [35], possibly due to the presence of human osteoblast and endothelial lineage cells in the SVF [36].

It is noteworthy that successful results, in terms of bone healing, have been achieved in different animal models, using either undifferentiated ADSCs or uncultured SVF, showing the huge potential of these progenitor cells in bone healing and formation [37]. Despite an increasing number of scientific data on ADSCs and their ability to repair and regenerate bone in vivo, to date there are very limited controlled clinical trials which have been performed with ADSCs in patients with bone-related disorders. Nevertheless, some successful results have been obtained in distinct trials where autologous ADSCs derived from anterior abdominal wall, when seeded onto either bioactive glass or $\beta$-tricalcium phosphate in combination with BMP-2, resulted in cranio-maxillofacial bone reconstruction [38, 39]. More, controlled trials definitely need to be carried out either with ADSCs or with adipose tissue-derived SVF.

\section{Growth Factors}

Growth factors are small proteins that have the ability to activate and induce the regeneration of new tissue to replace injured and damaged tissue. For this reason, these factors are being exploited in the field of bone tissue engineering. Growth factors, such as BMPs, stimulate the cells via the cell surface receptors and activate downstream signaling cascades causing cellular proliferation and/or differentiation.

BMPs regulate bone formation during skeletal development and play an important role in bone development, remodeling, and repair. BMPs are members of the transforming growth factor- $\beta$ superfamily of proteins and maintain bone mass during postnatal growth and participate actively in bone repair [40]. BMP-2 has been shown to maintain the osteoprogenitor cells, promote differentiation to osteoblasts, and is critical in bone healing [41]. There have been significant efforts to deliver BMPs in an efficient manner to regenerate bone, and commercial Food and Drug Administration(FDA)-approved recombinant (rh) BMP products are available such as OP- $1{ }^{\circledR}$ (BMP-7; Olympus Biotech, Lyon, France) or BMP-2 (infuse Bone Graft; Medtronic, Minneapolis, MN, USA). Pre-clinical and clinical studies using BMPs have been clearly successful $[42,43]$. As a result, FDA clearance has been granted to BMP-2 and BMP-7 for specific clinical applications such as fracture healing, long bone non-unions, spinal fusion, and periodontal as well as dental regeneration procedures [40].

However, there are certain limitations associated with the use and production of BMPs or other protein therapeutics. i) Increased dosage of BMP-2 has adverse health side effects. ii) rh BMPs are expensive and could be a burden on the patient. iii) rh BMPs may have traces of biologically active impurities. iv) rh BMPs could elicit undesirable immune responses. To overcome these limitations, a possible strategy would be to reduce the effective amount of rh BMP in the clinic and to replace them with other new molecules or to have a system of co-delivery with an enhancer of BMP's activity. These new molecules should have all the required bone regeneration qualities like BMP, be less expensive and easily available, have minimal to no side effects, have no contaminants, be stable, and should not trigger immune response.

Other molecules such as short peptides can also contribute towards efficient bone regeneration. Short peptides are segments of therapeutic proteins and have been investigated widely for tissue 
engineering purposes. In comparison to the growth factors such as BMPs, the short peptides exhibit a smaller size. They are synthesized in the laboratory and contain the active sequence of the parent molecule. They are more stable and less immunogenic due to their small size. For example, the BMP-derived short peptides are quiet stable, and they interact with BMPR-I and II which triggers the downstream signaling pathways [44]. Positive in vitro and in vivo results have been obtained with the short peptides, and these peptides have shown to have osteogenic ability [40, 45, 46]. Other short peptides have been synthesized based on the active sequence of the parent proteins such as collagen type 1, bone sialoprotein, osteopontin and osteogenic growth peptide. These works have been discussed well in recent reviews by Balmayor [40] and by Maia et al. [44].

Another class of emerging molecules is the small osteoinductive molecules that act as enhancer of growth factors. These small molecules have recently emerged as promising candidates for tissue regeneration. Due to their small size, they display low immunogenicity. These molecules could permeate or diffuse easily across the cell membrane, triggering the downstream signaling cascade. These molecules have been found to activate BMP signaling, stimulate the hedgehog $(\mathrm{Hh})$ pathway or influence the Wnt/betacatenin or cyclic adenosine monophosphate/ protein kinase A (cAMP/PKA) signaling pathways.

Dexamethasone, phenamil, oxysterols, purmorphasmine, fingolimod, lovastatin, atrovastatin, rosuvastatin, and simvastatin are examples for small osteogenic molecules reported thus far [40]. All these molecules display osteogenic properties in in vitro or in vivo models and have shown to increase the expression of bone-related genes, bone mineralization, and new bone formations. Moreover, these compounds have an additive effect when used in combination with BMPs. For example, phenamil has an additive effect with BMP-2 and BMP-7 in osteoblast differentiation and mineralization [47].

In our laboratory, we have shown that the small molecule $\mathrm{N}$ methyl pyrrolidone (NMP), which has a very low molecular weight $(99.1 \mathrm{~g} / \mathrm{mol})$ and is soluble both in water and organic solvent, could enhance BMP-2 action [48]. NMP is a FDA-approved injectable pharmaceutical excipient and is safe if used within the prescribed doses [49]. NMP has been shown to activate the boneforming activities of osteoblasts and decrease bone resorption of osteoclasts $[48,50]$. An in vivo study using rabbit calvarial defect showed significantly higher bone regeneration with NMP by increasing the activity of the natural locally deposited autologous BMP [48]. NMP at concentrations between 1 and $5 \mathrm{mmol} / \mathrm{l}$ enhances BMP activity two to eight times and is most efficient at low BMP concentrations. Using an in situ forming implants (ISFI) system; we developed a slow and sustained double delivery mechanism for rh BMP-2 and its enhancer NMP. Using the dual delivery ISFI system, rh BMP-2 and NMP were shown to bridge the critical size defect in the calvarial bone and aid in bone regeneration [51]. Thus enhancer small molecules like NMP could replace the high dose of BMPs and activate the action of the growth factors for efficient osteogenesis.

\section{Vascularization}

As for all tissue engineering approaches, vascularization is a limiting factor. For bone tissue engineering this aspect was reviewed recently [52] and can be facilitated on the level of growth factors or cell combinations. BMP-2, a key growth factor for bone tissue engineering, was shown to stimulate proliferation and tube formation of human aortic endothelial cells [53]. Such effects could also be of an indirect nature by induction of the angiogenic factor VEGF-A [54]. Double delivery of BMPs and VEGF was shown to increase bone formation even further [55]. In larger animals (beagles), the timing of the release of the individual factors had no effect on the orthotopic site. At an ectopic site, fast BMP release was superior in terms of new bone formation, and addition of VEGF had no effect [56].

Cellular strategies to promote vascularization in tissue engineering approaches have been reviewed recently [57], and the preferential use of pericytes have been highlighted [58]. The use and delivery of a combination of MSCs for bone formation and endothelial cells to form a microcapillary-like network was successfully realized by a two-stage seeding protocol to illustrate that clinically relevant progenitor sources can serve to generate highly functional microvascular networks for bone tissue engineering [59].

Taking together, by the combination of growth factors and different cell types, bone tissue engineering gets more and more complex and academic instead of clinically applicable to justify the efforts and costs for a wide range of patients, especially when considering that in the clinic autografts and vascularized bone grafts are successfully used since decades [60] and in direct competition to the use of engineered bone. In this context, a new strategy based on the avascular cartilage intermediate appears very promising for translation into the clinic since it recapitulates natural embryonic bone formation by endochondral ossification and is based on MSCs only [61].

\section{Bone Regeneration: Challenges}

Even though much work has been done in the field of bone tissue engineering, we could still improve our present understanding about scaffolds, cells, and growth factors. Here is a list of some of the challenges that we face and that need to be addressed:

- Tissue hypoxia: A key challenge in the clinical application of cell-based tissue-engineered bone implants is the poor diffusion of oxygen into avascular tissue [62]. Due to improper oxygen diffusion the bone regeneration is not efficient, in particular due to improper angiogenesis. Therefore, more studies investigating the ways to overcome tissue hypoxia should be performed.

- Improper angiogenesis: Therapeutic targeting of angiogenesis to treat non-healing bone defects will be essential for improved clinical skeletal outcomes. Treatments with erythropoietin (EPO) showed to have a good effect given the potential of EPO to induce cartilaginous callus formation and angiogenesis, re- 
sulting in enhanced endochondral ossification. Creation of bioengineered heterotrophic bone around new blood vessels as suggested by Cai and colleagues [55] and altering the levels of growth factors such as VEGF and BMP-2 to modulate bone repair is an interesting suggestion to enhance bone augmentation. The development of new vascular ingrowth therapies will definitely aid in fastening the repair of bone damage.

- Optimizing scaffolds: Future scaffolds should match the mechanical characteristics of bone. They should be non-immunogenic and biodegradable, and the degradation by-products should be cleared by the body without complications.

- Optimizing growth factors: At high doses, growth factors can result in adverse side effects such as soft tissue inflammation and swelling. However, it is probable that when used in reduced dose in combination with small chemical molecules (like NMP) it may stimulate the bone forming potential of the implanted cells, but the clinical evidence is lacking. Alternatively, the use of growth factors can be restricted to the pre-implantation cell expansion phase in order to enhance the regenerative potency of the implanted MSCs and thereby prevent possible side effects caused by in vivo application of growth factors [63].

- Translating laboratory results to clinical trials: Many of the in vitro techniques fail to mimic the cellular, molecular, physiological, and biomechanical intricacies present in the whole organism level. To mimic these, there is a need to utilize advanced in vivo approaches.

Moreover, each in vivo model has an inherent magnitude of factors that influence the appropriate animal use. While current technological developments in the biomaterials field create an exciting environment enabling further rapid progress, clinical translation is still a challenge also from the regulatory point of view. The therapeutic success of clinically relevant regenerative implants will largely depend on how the implanted cells are adapted to react to the hostile and hypoxic host environment into which they are placed.

In spite of all the challenges and optimizations that need to be addressed, bone tissue engineering is an expansive field, and new combination approaches are being developed continuously. The goal to deliver effective and economical bone regeneration therapeutic tools and techniques should be the utmost priority to reduce bone-related injuries and diseases.

\section{Author Contributions}

IB, CG, FEW: manuscript drafting, revisions and approval.

\section{Acknowledgments}

This research work performed by authors is funded by the Swiss National Science Foundation (31003A_140868) and (CR32I3_152809).

\section{Disclosure Statement}

The authors declare no potential conflicts of interest with respect to the authorship and/or with regard to the publication of this article.

\section{References}

1 Tytherleigh-Strong GM, Keating JF, Court-Brown CM: Extra-articular fractures of the proximal tibial diaphysis: Their epidemiology, management and outcome. J R Coll Surg Edinb 1997;42:334-338.

2 Black CR, Goriainov V, Gibbs D, Kanczler J, Tare RS, Oreffo RO: Bone tissue engineering. Curr Mol Biol Rep 2015;1:132-140.

$\checkmark 3$ Svedbom A, Hernlund E, Ivergard M, Compston J, Cooper C, Stenmark J, McCloskey EV, Jonsson B, Kanis JA; EU Review Panel of IOF: Osteoporosis in the European Union: a compendium of country-specific reports. Arch Osteoporos 2013;8:137.

$\checkmark 4$ Rosenwasser MP, Cuellar D: Medical management of osteoporosis and the surgeons' role. Injury 2016;47 (suppl 1):S62-64.

5 Murphy CM, O’Brien FJ, Little DG, Schindeler A: Cellscaffold interactions in the bone tissue engineering triad. Eur Cell Mater 2013;26:120-132.

6 Urist MR: Bone: Formation by autoinduction. Science 1965;150:893-899.

7 Gomez-Barrena E, Rosset P, Muller I, Giordano R, Bunu C, Layrolle P, Konttinen YT, Luyten FP: Bone regeneration: stem cell therapies and clinical studies in orthopaedics and traumatology. J Cell Mol Med 2011; 15:1266-1286.

8 Delloye C, Cornu O, Druez V, Barbier O: Bone allografts: what they can offer and what they cannot. J Bone Joint Surg Br 2007;89:574-579.
Rosset P, Deschaseaux F, Layrolle P: Cell therapy for bone repair. Orthop Traumatol Surg Res 2014; 100:S107-112.

10 Shields LB, Raque GH, Glassman SD, Campbell M, Vitaz T, Harpring J, Shields CB: Adverse effects associated with high-dose recombinant human bone morphogenetic protein-2 use in anterior cervical spine fusion. Spine (Phila Pa 1976) 2006;31:542-547.

11 Stegen S, van Gastel N, Carmeliet G: Bringing new life to damaged bone: The importance of angiogenesis in bone repair and regeneration. Bone 2015;70:19-27.

12 Williams DF: There is no such thing as a biocompatible material. Biomaterials 2014;35:10009-10014.

13 Damadzadeh B, Jabari H, Skrifvars M, Airola K, Moritz N, Vallittu PK: Effect of ceramic filler content on the mechanical and thermal behaviour of poly-1lactic acid and poly-l-lactic-co-glycolic acid composites for medical applications. J Mater Sci Mater Med 2010;21:2523-2531.

14 Akkouch A, Zhang Z, Rouabhia M: Engineering bone tissue using human dental pulp stem cells and an osteogenic collagen-hydroxyapatite-poly (1-lactide-coepsilon-caprolactone) scaffold. J Biomater Appl 2014; 28:922-936.

15 Cunniffe GM, Dickson GR, Partap S, Stanton KT, O'Brien FJ: Development and characterisation of a collagen nano-hydroxyapatite composite scaffold for bone tissue engineering. J Mater Sci Mater Med 2010; 21:2293-2298.
6 Friedenstein AJ, Gorskaja JF, Kulagina NN: Fibroblast precursors in normal and irradiated mouse hematopoietic organs. Exp Hematol 1976;4:267-274.

17 Almubarak S, Nethercott H, Freeberg M, Beaudon C, Jha A, Jackson W, Marcucio R, Miclau T, Healy K, Bahney C: Tissue engineering strategies for promoting vascularized bone regeneration. Bone 2016;83:197209.

18 Berner A, Henkel J, Woodruff MA, Steck R, Nerlich M, Schuetz MA, Hutmacher DW: Delayed minimally invasive injection of allogenic bone marrow stromal cell sheets regenerates large bone defects in an ovine preclinical animal model. Stem Cells Transl Med 2015;4: 503-512.

19 Yamada T, Yoshii T, Sotome S, Yuasa M, Kato T, Arai Y, Kawabata S, Tomizawa S, Sakaki K, Hirai T, Shinomiya $\mathrm{K}$, Okawa A: Hybrid grafting using bone marrow aspirate combined with porous beta-tricalcium phosphate and trephine bone for lumbar posterolateral spinal fusion: a prospective, comparative study versus local bone grafting. Spine (Phila Pa 1976) 2012;37: E174-179.

20 Damron TA, Lisle J, Craig T, Wade M, Silbert W, Cohen $\mathrm{H}$ : Ultraporous beta-tricalcium phosphate alone or combined with bone marrow aspirate for benign cavitary lesions: comparison in a prospective randomized clinical trial. J Bone Joint Surg Am 2013; 95:158-166. 
21 Russell TA, Leighton RK; Alpha-BSM Tibial Plateau Fracture Study Group: Comparison of autogenous bone graft and endothermic calcium phosphate cement for defect augmentation in tibial plateau fractures. A multicenter, prospective, randomized study. J Bone Joint Surg Am 2008;90:2057-2061.

22 Scherberich A, Muller AM, Schafer DJ, Banfi A, Martin I: Adipose tissue-derived progenitors for engineering osteogenic and vasculogenic grafts. J Cell Physiol 2010;225:348-353.

23 Zuk PA, Zhu M, Ashjian P, De Ugarte DA, Huang JI, Mizuno H, Alfonso ZC, Fraser JK, Benhaim P, Hedrick MH: Human adipose tissue is a source of multipotent stem cells. Mol Biol Cell 2002;13:4279-4295.

24 Barba M, Cicione C, Bernardini C, Michetti F, Lattanzi $\mathrm{W}$ : Adipose-derived mesenchymal cells for bone regereneration: state of the art. Biomed Res Int 2013; 2013:416391.

25 Lee RH, Kim B, Choi I, Kim H, Choi HS, Suh K, Bae YC, Jung JS: Characterization and expression analysis of mesenchymal stem cells from human bone marrow and adipose tissue. Cell Physiol Biochem 2004;14:311324.

26 Hung BP, Hutton DL, Kozielski KL, Bishop CJ, Naved B, Green JJ, Caplan AI, Gimble JM, Dorafshar AH, Grayson WL: Platelet-derived growth factor BB enhances osteogenesis of adipose-derived but not bone marrow-derived mesenchymal stromal/stem cells. Stem Cells 2015;33:2773-2784

27 Lee JW, Kim KJ, Kang KS, Chen S, Rhie JW, Cho DW: Development of a bone reconstruction technique using a solid free-form fabrication (SFF)-based drug releasing scaffold and adipose-derived stem cells. J Biomed Mater Res A 2013;101:1865-1875.

28 Samorezov JE, Headley EB, Everett CR, Alsberg E: Sustained presentation of BMP-2 enhances osteogenic differentiation of human adipose-derived stem cells in gelatin hydrogels. J Biomed Mater Res A 2016;104: 1387-1397.

29 Lee SJ, Kang SW, Do HJ, Han I, Shin DA, Kim JH, Lee $\mathrm{SH}$ : Enhancement of bone regeneration by gene delivery of BMP2/Runx2 bicistronic vector into adiposederived stromal cells. Biomaterials 2010;31:5652-5659.

30 Weimin P, Zheng C, Shuaijun J, Dan L, Jianchang Y, Yue H: Synergistic enhancement of bone regeneration by LMP-1 and HIF-1alpha delivered by adipose derived stem cells. Biotechnol Lett 2016;38:377-384.

-31 Liao HT, Lee MY, Tsai WW, Wang HC, Lu WC: Osteogenesis of adipose-derived stem cells on polycaprolactone-beta-tricalcium phosphate scaffold fabricated via selective laser sintering and surface coating with collagen type i. J Tissue Eng Regen Med 2013; doi: 10.1002/term.1811

-32 Zanetti AS, McCandless GT, Chan JY, Gimble JM, Hayes DJ: Characterization of novel akermanite: polycaprolactone scaffolds for human adipose-derived stem cells bone tissue engineering. J Tissue Eng Regen Med 2015;9:389-404.

33 Frohlich M, Grayson WL, Marolt D, Gimble JM, Kregar-Velikonja N, Vunjak-Novakovic G: Bone grafts engineered from human adipose-derived stem cells in perfusion bioreactor culture. Tissue Eng Part A 2010; 16:179-189.

-34 Silva AR, Paula AC, Martins TM, Goes AM, Pereria MM: Synergistic effect between bioactive glass foam and a perfusion bioreactor on osteogenic differentiation of human adipose stem cells. J Biomed Mater Res A 2014;102:818-827.

35 Papadimitropoulos A, Scherberich A, Guven S, Theilgaard N, Crooijmans HJ, Santini F, Scheffler K, Zallone A, Martin I: A 3D in vitro bone organ model using human progenitor cells. Eur Cell Mater 2011;21: 445-458; discussion 458.
36 Guven S, Mehrkens A, Saxer F, Schaefer DJ, Martinetti R, Martin I, Scherberich A: Engineering of large osteogenic grafts with rapid engraftment capacity using mesenchymal and endothelial progenitors from human adipose tissue. Biomaterials 2011;32:58015809.

37 Campana V, Milano G, Pagano E, Barba M, Cicione C, Salonna G, Lattanzi W, Logroscino G: Bone substitutes in orthopaedic surgery: from basic science to clinical practice. J Mater Sci Mater Med 2014;25:2445-2461.

38 Sandor GK, Numminen J, Wolff J, Thesleff T, Miettinen A, Tuovinen VJ, Mannerstrom B, Patrikoski M, Seppanen R, Miettinen S, Rautiainen M, Ohman J: Adipose stem cells used to reconstruct 13 cases with cranio-maxillofacial hard-tissue defects. Stem Cells Transl Med 2014;3:530-540.

39 Sandor GK, Tuovinen VJ, Wolff J, Patrikoski M, Jokinen J, Nieminen E, Mannerstrom B, Lappalainen OP, Seppanen R, Miettinen S: Adipose stem cell tissueengineered construct used to treat large anterior mandibular defect: a case report and review of the clinical application of good manufacturing practice-level adipose stem cells for bone regeneration. J Oral Maxillofac Surg 2013;71:938-950.

40 Balmayor ER: Targeted delivery as key for the success of small osteoinductive molecules. Adv Drug Deliv Rev 2015;94:13-27.

41 Rosen V: BMP2 signaling in bone development and repair. Cytokine Growth Factor Rev 2009;20:475-480.

42 Cipitria A, Reichert JC, Epari DR, Saifzadeh S, Berner A, Schell H, Mehta M, Schuetz MA, Duda GN, Hutmacher DW: Polycaprolactone scaffold and reduced rhBMP-7 dose for the regeneration of critical-sized defects in sheep tibiae. Biomaterials 2013;34:99609968.

43 Govender S, Csimma C, Genant HK, Valentin-Opran A, Amit Y, Arbel R, Aro H, Atar D, Bishay M, Borner MG, Chiron P, Choong P, Cinats J, Courtenay B, Feibel R, Geulette B, Gravel C, Haas N, Raschke M, Hammacher E, van der Velde D, Hardy P, Holt M, Josten C, Ketterl RL, Lindeque B, Lob G, Mathevon H, McCoy G, Marsh D, Miller R, Munting E, Oevre S, Nordsletten L, Patel A, Pohl A, Rennie W, Reynders P, Rommens PM, Rondia J, Rossouw WC, Daneel PJ, Ruff S, Ruter A, Santavirta S, Schildhauer TA, Gekle C, Schnettler R, Segal D, Seiler H, Snowdowne RB, Stapert J, Taglang G, Verdonk R, Vogels L, Weckbach A, Wentzensen A, Wisniewski T; BMP-2 Evaluation in Surgery for Tibial Trauma (BESTT) Study Group: Recombinant human bone morphogenetic protein-2 for treatment of open tibial fractures: a prospective, controlled, randomized study of four hundred and fifty patients. J Bone Joint Surg Am 2002;84-A:2123-2134.

44 Maia FR, Bidarra SJ, Granja PL, Barrias CC: Functionalization of biomaterials with small osteoinductive moieties. Acta Biomater 2013;9:8773-8789.

45 Bergeron E, Leblanc E, Drevelle O, Giguere R, Beauvais S, Grenier G, Faucheux N: The evaluation of ectopic bone formation induced by delivery systems for bone morphogenetic protein-9 or its derived peptide. Tissue Eng Part A 2012;18:342-352.

46 Li J, Hong J, Zheng Q, Guo X, Lan S, Cui F, Pan H, Zou Z, Chen C: Repair of rat cranial bone defects with nHAC/PLLA and BMP-2-related peptide or rhBMP-2. J Orthop Res 2011;29:1745-1752.

47 Park KW, Waki H, Kim WK, Davies BS, Young SG, Parhami F, Tontonoz P: The small molecule phenamil induces osteoblast differentiation and mineralization. Mol Cell Biol 2009;29:3905-3914.
48 Miguel BS, Ghayor C, Ehrbar M, Jung RE, Zwahlen RA, Hortschansky P, Schmoekel HG, Weber FE: Nmethyl pyrrolidone as a potent bone morphogenetic protein enhancer for bone tissue regeneration. Tissue Eng Part A 2009;15:2955-2963.

49 Lee KP, Chromey NC, Culik R, Barnes JR, Schneider PW: Toxicity of n-methyl-2-pyrrolidone (NMP): teratogenic, subchronic, and two-year inhalation studies. Fundam Appl Toxicol 1987;9:222-235.

50 Ghayor C, Correro RM, Lange K, Karfeld-Sulzer LS, Gratz KW, Weber FE: Inhibition of osteoclast differentiation and bone resorption by $\mathrm{N}$-methylpyrrolidone. J Biol Chem 2011;286:24458-24466.

51 Karfeld-Sulzer LS, Ghayor C, Siegenthaler B, de Wild M, Leroux JC, Weber FE: N-methyl pyrrolidone/bone morphogenetic protein-2 double delivery with in situ forming implants. J Control Release 2015;203:181-188.

52 Mercado-Pagan AE, Stahl AM, Shanjani Y, Yang Y: Vascularization in bone tissue engineering constructs. Ann Biomed Eng 2015;43:718-729.

53 Langenfeld EM, Langenfeld J: Bone morphogenetic protein-2 stimulates angiogenesis in developing tumors. Mol Cancer Res 2004;2:141-149.

54 Yeh LC, Lee JC: Osteogenic protein-1 increases gene expression of vascular endothelial growth factor in primary cultures of fetal rat calvaria cells. Mol Cell Endocrinol 1999;153:113-124.

55 Cai WX, Zheng LW, Li CL, Ma L, Ehrbar M, Weber FE, Zwahlen RA: Effect of different rhBMP-2 and TG-VEGF ratios on the formation of heterotopic bone and neovessels. Biomed Res Int 2014;2014:571510.

56 Geuze RE, Theyse LF, Kempen DH, Hazewinkel HA, Kraak HY, Oner FC, Dhert WJ, Alblas J: A differential effect of bone morphogenetic protein-2 and vascular endothelial growth factor release timing on osteogenesis at ectopic and orthotopic sites in a large-animal model. Tissue Eng Part A 2012;18:2052-2062.

57 Liu Y, Chan JK, Teoh SH: Review of vascularised bone tissue-engineering strategies with a focus on co-culture systems. J Tissue Eng Regen Med 2015;9:85-105.

58 Costa-Almeida R, Granja PL, Soares R, Guerreiro SG Cellular strategies to promote vascularisation in tissue engineering applications. Eur Cell Mater 2014;28:5166; discussion 66-57.

59 Tsigkou O, Pomerantseva I, Spencer JA, Redondo PA, Hart AR, O'Doherty E, Lin Y, Friedrich CC, Daheron L, Lin CP, Sundback CA, Vacanti JP, Neville C: Engineered vascularized bone grafts. Proc Natl Acad Sci U S A 2010;107:3311-3316.

60 Moran CG, Wood MB: Vascularized bone autografts. Orthop Rev 1993;22:187-197.

61 Scotti C, Piccinini E, Takizawa H, Todorov A, Bourgine P, Papadimitropoulos A, Barbero A, Manz MG, Martin I: Engineering of a functional bone organ through endochondral ossification. Proc Natl Acad Sci U S A 2013;110:3997-4002.

62 Stiers PJ, van Gastel N, Carmeliet G: Targeting the hypoxic response in bone tissue engineering: a balance between supply and consumption to improve bone regeneration. Mol Cell Endocrinol 2016;432:96-105.

63 van Gastel N, Stegen S, Stockmans I, Moermans K, Schrooten J, Graf D, Luyten FP, Carmeliet G: Expansion of murine periosteal progenitor cells with fibroblast growth factor 2 reveals an intrinsic endochondral ossification program mediated by bone morphogenetic protein 2. Stem Cells 2014;32:2407-2418. 